\title{
Adolescence and Youth
}

Adolescence is a transitional period marked by substantial changes in physical maturation, cognitive abilities, and social interactions, often indicating an age period of the life course between puberty and adulthood, which leads from childhood and puberty into transition to legal adulthood and citizenship. The term adolescence was introduced to social science by G. Stanley Hall in 1904. He was the first psychologist to advance a psychology of adolescence in its own right and to use scientific methods to study youth. He defined the period of adolescence as beginning at puberty at about 12 or 13 years, and ending between 22 years to 25 years of age. In primitive societies rites of passage traditionally marked a clear move from childhood to adulthood. In the psychological theories of Sigmund Freud, Carl Jung, Jean Piaget and Erik H. Erikson adolescence is presented as reflecting an important developmental process.) In his book, The Adolescent Society, sociologist James Samuel Coleman (1926 - 1994) describes a teenager subculture, which includes a large segment of the population for a fairly long period of time. He expanded the focus from individuals to social groups in schools. With his theory of the ecology of human development Urie Bronfenbrenner (1979) has had a widespread influence on the study of youth and adolescents. He argued that a child develops through interactions with his or her "proximal" social environments, such as families, peer groups, schools, neighborhoods, after-school groups, faith groups, and the many other social settings. Later on young people are affected by larger "distal" societal systems like communication networks, social and cultural institutions and organizations, economy and politics (Bronfenbrenner, 2005).

The main theories and methodologies of research on adolescence have tend to come from developmental psychology and life-course sociology, and there have been important contributions from areas of the biomedical sciences, including adolescent medicine. The main interest of developmental scientists has been in the ages from ten to twenty, including the considerable physical and physiological changes of puberty, when the interdependency of biology and cognitive abilities, social relationships, and motivation is formed. Other areas focusing on specific issues for research on adolescence and youth research include the social and cultural construction of youth, youth as a state of being, as a distinct category of subjectivity and identity, as a form of cultural expression, as a stage of life, as an element of social-cultural capital, and as socioeconomic resource.

Cultural analysis of youth-related phenomena has long been used in the social sciences. In AngloAmerican literature there are separate categories for young adolescents (10-14), teens (15-19), and 
young adults (20-24). The term tweens was introduced in the 1990s to refer to prepubertal young people aged from 10 to 12 . Some approach youth in relational terms, with reference to the social processes whereby age is socially constructed, institutionalized, and controlled in historically and culturally specific ways (Furlong \& Cartmel, 2007; White, Wyn and Robards, 2017). The sociological explanations of adolescence include functionalist, subcultural, postmodernist, and political economy models with a multifaceted approach drawing at times on the psychological approach of Erikson's identity theory (Côté \& Levine, 2016). Jeffrey Arnett's critized theory proposes that what had been generally referred to as late adolescence and post adolescence is a new sociopsychological stage, emerging adulthood (Arnett, al., 2011). Research relating to youth and adolescence covers basic aspects of biological, cognitive and social development from early adolescence through prolonged transition to adulthood or emerging adulthood. This broad area includes culture, families, achievement, schools, work, and careers, peers, romantic relationships, lifestyles, puberty, the brain and cognitive development, the self and identity, emotion, and personality, gender and sexuality, moral development, values, and religion.

The developmental period of adolescence can lead to increased incidence of unintentional injuries and violence, alcohol and drug abuse, unintended pregnancy and sexually transmitted diseases. Research on risk-taking behavior and decision-making is connected with research on brain development during adolescence. The affective instability of early adolescence is explained as a result of an imbalance in the development of brain regions or as an impact of pubertal hormones during early adolescence. Adolescents' social and personal relationships involve the nature and influence of a plurality of relationships including family, peers, friends, and sexual and romantic relations. Adolescents' mental health involves psychopathology driving deviance, violence, crime, risk, victimization, disabilities, and positive youth development. There is an abundance of social institutions serving adolescents by providing socializing contexts, media, legal systems, religious groups, justice systems, medical fields, economic structures, and youth organizations.

In sociological research recognition of environmental interactions and ecological perspectives on human development are important organizational markers of youth and adolescence. For example schooling marks the transition from childhood to adolescence at different levels of educational institutions. In psychological research the beginning of puberty and cognitive development are taken as developmental signals for adolescence. Phases can appear differently between boys and girls being gender and culture-specific. In pubertal development there are regression stages involving interactions between individual children, other people and social contexts. In various 
societies and cultures different legal conventions and social traditions are used for identifying adolescents often emphasizing chronological age. However there are substantial individual differences both in psychological development and in organisational transitions from childhood into adolescence and to adulthood. These phases can differ in age levels and in accordance with sociological transitions.

Early adolescence is a critical period linked to identity formation in relations with the family and the outside world. According to the theory of cognitive development and growth of logical thinking between the ages of 11 and 12 there is a decisive transition from concrete logical operations to formal operations in which the subject is able to formulate clear propositions and make their own choices (Inhelder \& Piaget, 1958). Modern society offers adolescents a large range of models from which they must make their own choices. Anxiety is a part of adolescent identity development. Adolescents need to find their identities to help them with decisions such as choosing a profession, having a family, and adopting acceptable citizenship values and roles. In his book Youth and crisis Erikson (1968) describes the search for identity as the principal crisis of adolescence. According to Erikson every human being goes through the stages to achieve full development. He argues that each age has a different psychosocial crisis to resolve. During their identity formation adolescents must make decisions on personal, occupational, sexual, and ideological commitments.

The environment in which a young person lives is critical especially in the success or failure of identity formation. According to Erikson the psychosocial moratorium is a period of time, during which a person has the opportunity to try out numerous identities and roles, before firmly committing to one, which is the final stage of adolescence identity development. If the young don't have the chance of moratorium, there is a risk of confusion about their identity and their role in society. (Erikson, 1956; 1968.) Erikson commented on issues of social protest and changing gender roles that were particular to the 1960s. As the culture changes, new kinds of identity questions arise. Research on identity status and different approaches to identity formation include focusing on the processes and patterns of identity development, and for example the similarities and differences in how females and males form their sense of identity (Marcia, et al. 1993).

From the 1980s onward, life course theory was developed. Life-course research on youth and adolescence focuses on the relationship between institutions and individuals across the life span and helps to clarify the impact of modernization on the shaping of biographies. A biographical approach to the youth life-course pictures the holistic and dynamic character of young people. The focus is 
on transitions to adulthood in the different domains of life, including family, education and employment. Life-course theories conceive youth as a series of processes in the transition to adult life.

It has been proposed that the youth life-course should be rethought in the light of the extension of the transition to adult independence, (Bynner, 2005; Côté \& Bynner, 2008). A further reason for rethinking youth is based on seeing it as a social construct. The form the life course varies significantly across different societies, time periods and cultural contexts. Many of the meanings, that are associated with youth, are changing. The period that corresponds to youth is ever more elastic. On the one hand, childhood seems to be blurring into youth. There is anxiety about the 'disappearance' of childhood, in which the media and popular culture are seen as the destroyers of children's innocence. This argument has taken on a renewed force in recent years, not least in response to children's growing access to consumer and media culture. On the other hand, the emergence of digital/social media implies a change in peoples's communucation, also indicating a further need for rethinking youth. There is increasing blurring of the boundary between youth and adulthood. For example music, like punk and heavy metal, that was once identified with youth are now attracting several generations as are youth fashion and the fitness industry. The cultural meanings of adolescence are therefore no longer clearly defined.

As a state of transition, the status of youth seems to have become more uncertain. The extended transition to adulthood continues often now into the thirties. Many young people, especially in the Western world, are leaving the family home at an older age, and settling down into stable jobs and relationships at a later age than previous generations. The transition to adulthood has also become precarious and significantly unstable. Adulthood is less easily attained and for many is also less desirable than it has used to be. The extended educational period of modern societies questions whether adolescence is lengthened or whether a new developmental stage has emerged.

\section{References}

Arnett, J. J., Kloep, M., Hendry, L.B., Tanner J.L. (2011) Debating Emerging Adulthood: Stage or Process? Oxford University Press, New York.

Bronfenbrenner, U. (ed.) (2005) Making Human Beings Human: Bioecological Perspectives on Human Development. Sage, Thousand Oaks, CA. 
Bynner, J. (2005) Rethinking the Youth Phase of the Life-Course: The Case for Emerging Adulthood? Journal of Youth Studies 8 (2005): 367-384.

Coleman, J. S. (1961) Adolescent society: The social life of the teenager and its impact on education. Free Press, New York.

Côte, J. and Bynner, J. (2008)) 'Exclusion from Emerging Adulthood: UK and Canadian Perspectives on Structure and Agency in the Transition to Adulthood', Journal of Youth Studies, 11 (3), 251-268.

Côté, J.E., Levine, C. (2016) Identity Formation, Youth, and Development: A Simplified Approach. Psychology Press, New York and London.

Erikson, E. H. (1956) The problem of ego identity. Journal of the American Psychoanalytic Association, 4, 56-121.

Erikson, E.H. (1968). Identity: Youth and crisis. W. W. Norton \& Company, New York.

Furlong, A. \& Cartmel, F. (2007) Young People and Social Change: New Perspectives. 2d ed. Open University Press, Maidenhead, UK.

Hall, G. S. (1904) Adolescence: Its psychology and its relations to physiology, anthropology, sociology, sex, crime, religion and education. Appleton, New York.

Inhelder, B., \& Piaget, J. (1958) The Growth of Logical Thinking from Childhood to Adolescence. Basic Books, New York.

Marcia, J. E., Waterman, A. S., Matteson, D. R., Archer, S. L. \& Orlofsky, J. L. (1993) Ego

Identity: A Handbook for Psychosocial Research. Springer-Verlag, New York.

White, R., Wyn, J., Robards, B. (2017)Youth and Society. Fourth Edition Oxford University Press, Oxford. 